\title{
Design for Elderly Friendly: Mobile Phone Application and Design that Suitable for Elderly
}

\author{
Mohamad Faisal \\ Mohamed Yusof \\ Faculty of Computer and \\ Mathematical Science \\ Universiti Teknologi MARA \\ Shah Alam, Malaysia
}

\author{
Nurhanani Romli \\ Department Shariah and \\ Economics \\ University of Malaya \\ Kuala Lumpur, Malaysia
}

\author{
Mohd Faiz Mohamed \\ Yusof \\ Academy of Contemporary \\ Islamic Studies \\ Universiti Teknologi MARA \\ Shah Alam, Malaysia
}

\begin{abstract}
The mobile phone design currently is always lack of concern towards the usability of the elderly. The elderly always having problem in understanding and using the mobile phone cause by this lack of study in understanding the needs of the older people. This paper provides the information related with the concept and issues related with the mobile phone design. The other topic in this paper is the application that suitable to be design in the mobile phone for the elderly. The function that need by this elderly is limited compare to the younger people. The elderly needs the mobile phones that have the design that suitable with their needs without concerning about the fashion or styles.
\end{abstract}

\section{General Terms}

Mobile Phone, Elderly

\section{Keywords}

Application, Audio, Cognitive, Dexterity, Impairment, Usability, Visual

\section{INTRODUCTION}

The innovation of mobile technology gives huge impact towards people. The Y generation might not have the problem in using and understanding the technology but some of the people from the $\mathrm{X}$ generation cannot cater with the development of the technology due to some problem related with the design of the mobile phones. It is important for the organization to understands and consider to all the age group in developing the mobile phone.

The focus on developing the user interface and design of mobile phones for elderly is by understanding the ability of the user. The focus on this paper is to understanding the ability target user that is the elderly. The elderly have different abilities with the young people. The methods on designing the mobile and user interface for elderly should be different from the younger user. The understanding about the difference between all groups of age will provide the user satisfaction for all group of age. In term of commercial the elderly user have potentially a very large customer based [5]. So putting the focus on the needs of elderly can increase the revenue of the organization in the future. This paper will focus on the concept, issues, application and design that suitable in choosing the mobile for elderly.

\section{CONCEPT AND ISSUES OF MOBILE PHONE DESIGN AND APPLICATION}

This section will focused on the concept of the mobile phone design and application for elderly. The elderly have some disabilities in using the mobile devices and technology. There are certain needs that should be considered to fulfill the user satisfaction for the older people.

\subsection{Adaptation Of The Older People}

\section{Towards The Mobile Devices}

The mobile technology development growing rapidly with the development of the smartphones, $3 \mathrm{G}$ and faster internet technology. This development leaves impacts towards the younger people and elderly. Back years before elderly are not interested with the mobile technology, they usually only use mobile phones to obtain assistance in emergencies. This stereotype is no longer available. Nowadays many elderly use mobile phones as social interaction tools ([2] : [3]).

With the fast development of technology the elderly can use the mobile application for internet searching, social network and connecting with their families and friends.

\subsection{Understanding The Elderly Abilities}

The report from Alan F. [6] shows that elderly have significantly different and dynamically changing needs. There are several types of elderly.

- $\quad$ Fit Older People - This elderly will not consider themselves as disable but functionality of whose they needs and wants are different to those they had when they were younger.

- $\quad$ Frail Older People - This type of elderly who be considered as have the severe disabilities and have the general reduction in their other functionalities.

- $\quad$ Disable person who grow older - This type of older people have along term disabilities have affected the ageing process and type of people who ability to function can be critically dependent on their other faculties.

According to Henk [5] the elderly are least likely using the internet. They only use interface for practical purpose like travel, finance, education and shopping and this is because elderly usually feels uncomfortable using the mobile technology.

The most important thing to consider in designing for elderly is related with reliability and this deliver the functionality. This reliability can be achieved through robustness, reducing 
and facilitating from and offering the error explanation. The elderly also attracted to the product that can offer the personalization factor. This product can also accommodate the need of elderly personally [1].

The four context that should be look in designing the mobile for elderly [1].

- Physical context- constraint such as vision, hearing and dexterities.

- Cognitive context- the abilities of the elderly the mental model underlying mobile phones menus.

- Social context- understanding their main social contact.

- Technology context- mobile infrastructure including the available network.

\subsection{Issues in Selecting the Mobile Application And Design For Elderly}

There are several issues that related with the elderly in selecting and choosing the mobile phones. Reduce in the visual and physical ability will affect the process of selecting the mobile phone.

\subsubsection{Button Design}

Study by Karen [7] show that the elderly preferred the small phone with the large button. This is because due to the increase of the age the elderly visual ability is reduces. This will cause the problem when the elderly wants to make a call or enter the phone number due to small button.

With the increase of age the elderly usually facing the problem relating with the dynamic visual acuity such as lost of visual decrement. The element of visual decrement cause the problem to the elderly on perceive small element on a mobile phone button [5].

The small button design also cause the problem towards the elderly by causing the elderly to push the wrong number and difficult to recognize the character of the icon in the mobile phones. For the emergency situation it will affect the elderly on making the call because the small button that crammed together will cause the elderly fail to push the real button especially in a very stressful situation.

The button design for the mobile phone is unsuitable for the elderly this will effect them when they are trying to sent the message to others. For example to type the b letter the user need to push the 2 button twice. This might be suitable for the young user but for elderly some of them are panic in typing the message and unable to sent the message [4].

The elderly also require the good spacing between the buttons to ensure the push the right button. This spacing will help to prevent the elderly the push the wrong button and causing the to call the wrong number.

The elderly are not favorable towards the button on the side of the mobile phones. These will accidently lead them to activated something that is not require.

\subsubsection{Display Design}

The display design plays important roles in selecting the mobile for the elderly. The display size is the physical characteristics but also has a significant potential complexity implication [1].
The elderly preferred the larger fonts and the bigger icons. The text sizes for the mobile phone cause the elderly hard on reading them. Even with the corrective lens the elderly found that it is hard to read from the mobile phones.

The menus design also should be considered in selecting the mobile phones for the elderly. The study by Sri Kurniawan [4] found that the elderly find that the mobile phones consist with too many unnecessary menus for elderly. This lack of understanding for the menu cause the elderly has to rely on the other people to fill their address book at their mobile phones.

Older people are not familiar with the mobile infrastructure, and this causes them some problem to understand the menu design. The complex menu design will cause the elderly to have the problem in understanding the menu.

\subsubsection{Auditory Acuity}

The elderly faced the problem with reduced of the auditory acuity in particular sensitive to pure tones and high frequency tones. The ability of the older people to hear is limited. Instead of to take an action during the phone ringing the elderly might just deny it because they unfamiliar with the sound.

The elderly also might face some problem in hearing their mobile phone ringtones in the crowded situation. This is because during the crowded situation it is hard for the people to catch the sound of the ringtones.

This is different in the silence place; because the elderly might want to reduce the volume of the ringtones to make sure they are not shock with the volume of the ringtones.

\subsubsection{Device design}

The older women preferred to have the bright colored and bulkier phones so they can put it on their handbag or clutch.

This elderly usually not concern about the design unless it fulfill their needs. The size of the mobile phones also will cause the elderly hard in grasp the mobile phones.

\subsubsection{Motor Impairment}

As we understand the elderly have some motor impairment problem. This motor impairment will cause the elderly have reduced fine motor control, muscle strength, and the pincher strength. So elderly ability to use the mobile phones are different with the younger people. The elderly tended to be slow in completing the motor-muscle-based task [7] and this cause elderly may have the problem in push the button or drag manipulation.

The elderly also have the slower response time. The mobile interface usually will not react with the small movement. For example when the user wants to type c letter the user have to push button 2 for three times, cause by this slower movement instead of getting the $c$ letter the user might get the $a$ or $b$ letter.

\subsubsection{Cognition Impairment}

The cognitive process decline with the age and this include the attention process, working memory, and problem solving [4]. With reduce in cognition; elderly might have the problem with attention limit and the working memory. The elderly usually cannot understand the menu because elderly usually thought that menu was design with too many complex movements. 
The elderly usually faced the problem with the cognition. The ability to remember and learning the new techniques also reduce with the dementia and memory dysfunction and this cause them to have problem in remembering the phone numbers and cause them to bring a phone book [3].

\subsubsection{Function Limitation}

The function limitation usually related with the level of confidence for the elder user in using the mobile phone. As we understand the elderly usually lack of experience in using the ICT technology. This will reduce the confidence level on the elderly user to use the mobile phones.

Elderly are usually not being exposed to use the ICT technology as much as the younger generation. This cause them more trust the younger people to help them to use the mobile phone. They unlikely to understand the methods and process to used the mobile phones.

\section{APPLICATION FOR ELDERLY FRIENDLY DESIGN}

The design for the elderly mobile phones should fulfill all the needs by the elderly. The elderly essential function for mobile phones is to make a call and receive a phone call. These are the necessary attribute that should have in the mobile phone. The non-essential but desirable function such as the emergency speed dial, alarm, scheduling function and text messaging should be put as the second priorities. The most important things are to fulfill the essential function [7].

\subsection{Non-essential function}

Apart from that there are several application that can improve the mobile phone for the elderly. The non-essential functions are desirable and can improve the elderly mobile phone.

- Calendar -The calendar can help in stores the appointment with the doctor and friends. This also can prevent the elderly from forgetting the appointment cause by their reduce of cognition abilities.

- $\quad$ Address book- this address book can help in storing the information for the friends and family. This address book should be easily understand by the user so that they can use this address book independently without require help from others. This feature can replace the heavy paper based address book that the older person tends to carry around [4].

- Notes - this can help in putting the information about the short-term notes such as shopping list.

- $\quad$ Reminder alarm -this will help the elderly to remind them about the appointments and the other information. This application also can help them in remembering them the time to taking the medication.

- Emergency - this will help them to call the emergency department if the emergency happened.

\section{DESIGNS FOR ELDERLY FRIENDLY MOBILE PHONES}

There are several improvements in design in order to provide more user-friendly design towards the elderly. The issues with the mobile phone should be take into accounts to ensure that the elderly is satisfied with the design that be created for the specific target that is elderly.

\subsection{Visual Design}

The first visual design that requires changing in order to fulfill the needs of the elderly is bigger text on screen. The elderly needs to have the bigger fonts on their phones. According to [7] the elderly preferred to have 12-point fonts and the $25 \mathrm{~mm}$ for icons. The ([4] \& [7]) suggested that the user should have the control over the size of font, color and the contrast setting.

Secondly the elderly needs the larger screen size. The increase of the age of the user cause reduce in their visual this cause the elderly needs the larger screen size.

Thirdly the elderly require the bigger text on keys and button. This is important to reduce the confusion and cause the elderly false in enter the phone number. The wrong input during entering the phone number will cause the problem especially during emergency.

Fourth is the more color contrast. The color contrast will help the elderly in differentiate the menu in the phone. The lack of contrast in color will cause the confusion and wrong choice of menu.

Fifth are the bigger phones. The elderly usually doesn't concern about the sense of style. They usually need the bigger size of phone so they can easily bring the phone and the bigger phone will reduce the possibilities of slip.

Lastly the elderly are having the problem with the motor impair, so their process of cognition is slower than the young people. This is important for the phone lighting on screen do not fade too quickly.

\subsection{Cognitive Design}

For cognitive design the phone should have fewer functions. This is because the elderly only use the phone for important use. There is no need to put so many functions for phone design for elderly. This less function in the mobile phone will help the elderly to easy remember the menu paths. Other thing that should be considered is to provide the button to adjust volume and ring. This is because the elderly need to control the volume of the phone so many times. It is easier if the elderly can just change the volume easily.

\subsection{Dexterity Design}

In the dexterity aspects, the elderly needs the bigger keypad and buttons. The bigger keys and button will help the elderly with reduce of visual can identified the entire button and reduce the probability in making the mistakes during using the mobile phones. The elderly felt that large button were extremely important to any devices they would use [1].

The button also should be further apart so the elderly will not make mistakes when push the buttons. The keypad must give the tactile feedback when pressed to ensure the user know that the button is successfully been pressed.

\subsection{Audio Design}

The elderly need the loud ringtones to ensure they are aware if the phone is ringing. Elderly usually have the problem with the hearing; with the loud ringtones can reduce the probability of the elderly not picking up the phones. The addition with the earpiece or hearing compatibility will help the elderly taking the call on the crowd place. With the use of earpiece the elderly can hear even in the loud spaces. 


\section{REFERENCES}

[1] Baecher, R.M., Wu, \& Masimmi, M. 2007. Using participatory activities with senior to critique, build and evaluate mobile phones, ACM.

[2] Conci, M., Pianesi, F., \& Zancanaro, M. 2009. Useful, social and enjoyable: Mobile phones adoption by older people, Lecture notes in computer science (Vol. 5726/2009,pp 63-76)

[3] Gelberdom, J.H., Van Dyk, T.J., \& Van Biljon, J.A. 2010. Mobile phone adoption: Do existing model do capture the actual usage of the older adult? Fountains of computing research, proceedings of SAICSIT 2010 Annual Research Conference of south African institute of computer scientist and information technologist: ACM international conference proceedings series.
[4] .Kurniawan, S. 2008. Older People and mobile phones : A multi-method investigation, Elsevier science.

[5] Nap, H.H., IJsselsteijn, W., Kort, Y.D. , Poels, K. 2007. Digital games design for elderly users. Proceedings of the 2007 conference on future play. 15-17 November 2007, Toronto, Canada, ACM.

[6] Newell, A.F., Gregor, P., Zajicek, M. 2002. Designing for dynamic diversity-interfaces for older people, ACM.

[7] Renaud, K., DYK, T.B., Biljon, J.V. 2012. Mosesmethod for selecting senior mobile phones: supporting design and choices for elderly, ACM. 